This is a postprint version of the following published document:

García, N., González, E., Baselga, J. \& Bravo, J. (2003). Critical thickness estimation in ISO-MC cards injection using CAE tools. Journal of Materials Processing Technology, 143-144, pp. 491-494.

DOI: 10.1016/S0924-0136(03)00303-0

(C) Elsevier, 2003

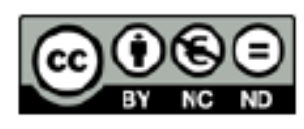

This work is licensed under a Creative Commons Attribution-NonCommercialNoDerivatives 4.0 International License. 


\title{
Critical thickness estimation in ISO-MC cards injection using CAE tools
}

\author{
Nélida García, Esther González, Juan Baselga*, Julio Bravo \\ Instituto de Tecnología Química y Materiales, Universidad Carlos III de Madrid, Avda. Universidad, 30, 28911 Leganés, Spain
}

\begin{abstract}
Injection moulding is a widely used polymer processing operation because of its ability to produce net-shaped components of good dimensional accuracy with a relatively short cycle time. Nevertheless, only few industries use CAE tools to optimise the injection process or to design the mould. Today, many industries have more confidence in their know-how than in the prediction on a commercial simulation software package. In this work we use C-MOLD to estimate the critical thickness for injection by studying the flow parameters in the thinnest section point of the ISO-MC card. We simulated the process with the geometry of a microchip credit card, which has a minimum thickness of $250 \mu \mathrm{m}$ (memory microchip area thickness), and studied the variation of different process parameters as this thickness increased. The maximum thickness was fixed at $800 \mu \mathrm{m}$ (global thickness) and the minimum thickness was modified from 250 to $500 \mu \mathrm{m}$. Different injection points and filling times were used to optimise the process. The pressure and temperature variations during the filling process are the most sensitive parameter. The plot of these parameters versus the minimum thickness allowed us to estimate the critical thickness of 360-390 $\mu \mathrm{m}$ for this geometry using different ABS plastics formulations. The plots show how the magnitudes are stabilised in a plateau when the thickness is higher than $390 \mu \mathrm{m}$ but they increase as the thickness decreases below $360 \mu \mathrm{m}$.
\end{abstract}

Keywords

C-MOLD; Injection moulding; CAE tools; Critical thickness

\section{Introduction}

The use of plastic materials and injection moulding processes has been growing at a tremendous rate over the past two decades. Some features that characterise injection moulding are: short product cycle, excellent surface and easily moulded complicated shape. The injection moulding process involves the injection of a polymer melt into a mould where the melt cools and solidifies Although injection moulding is one of the most widely used methods in plastic manufacturing, the product process is easily affected by the $\mathrm{fl} \mathrm{w}$ type of the melt, the heat transfer effect, material properties and the specifi geometry of the mould. However, with the increasing use of computers in design engineering, the amount of commercially available software to simulate the melt plastic behaviour in the mould has also increased [1]. To the versatile user, simulations can produce a variety of results on all aspects of the injection process and they can implement the traditional intuitive method of mould design. Research on plastic injection moulding has included a growing number of papers on optimisation algorithms to assist the designer in the work of mould and part design [2-6]. Many other authors have used these software tools to

\footnotetext{
* Corresponding author. Tel.: +34-1-624-94-67; fax: +34-1-624-94-30. E-mail address: jbaselga@ing.uc3m.es (J. Baselga).
}

optimise injection process variables like the minimum pressure [7], the reduction of distortion balancing the $\mathrm{fl} \mathrm{w}$ in the mould cavity [8], the fibr orientation in reinforced plastics $[9,10]$. All these work tried to bring light to the injection process, which was considered by some to be a "black art" known by only a handful of experts. It is also possible to use these computer aided engineering (CAE) tools to test some rules based on the knowledge acquired so far.

In this work we use C-MOLD to estimate the critical thickness for injection by studying the $\mathrm{fl} \mathrm{w}$ parameters in the thinnest section point for of ISO-MC card. We use a new method to estimate the critical conditions by plotting different parameters versus the thickness [11-13]. The value of the estimated critical thickness is in agreement with the knowledge acquired.

\section{Computer modelling details}

The microchip credit card is fla with a maximum thickness of $800 \mu \mathrm{m}$ (global thickness for more than $95 \%$ of the surface). This dimension was fi ed for all the geometrical models. On the manufactured card there is a square area with a reduced thickness of $600 \mu \mathrm{m}$ inside which is a circular area with a minimum thickness of $250 \mu \mathrm{m}$. This was modifie in the different geometrical models built. The 


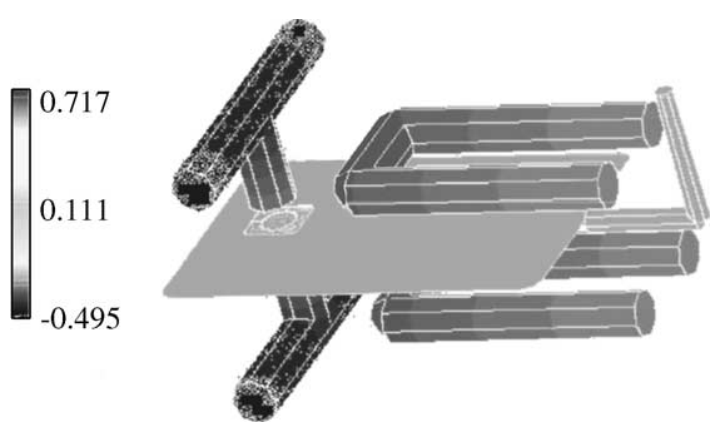

Fig. 1. ISO-MC card geometry with runner and cooling channel.

minimum thicknesses used were $250,270,285,300,330$, $360,400,500$ and $600 \mu \mathrm{m}$.

Fig. 1 shows the card geometry, the runner and the cooling channel. The $\mathrm{T}$ geometry channels (Baffles placed over and under the microchip area warm the zone while the $\mathrm{U}$ geometry cooling channels cool the mould on the fla area.

Two sizes of three-node triangular elements were used to generate the mesh. The size of the microchip area element was $0.6 \mathrm{~mm}$ and it changed progressively to $3 \mathrm{~mm}$ for the rest of the card geometry. Two-node linear tubular elements were used for the runner and the cooling channels. Fig. 2 shows the mesh and a detail of this in the microchip area. The mesh includes more than 2000 nodes and 3000 part elements.

Three different materials based on low viscosity acrylonitrile butadiene styrene (ABS) were selected. Their commercial names are Cyclolac T-XS300001 (General Electric), Cyclolac G-360 (General Electric) and Magnum 4455 (Dow Chemical).

Different injection points were used to optimise the process but only the gate position showed in Fig. 1 was taken into account because it produces the best results.

There is an optimal fil time for any process. If the fil time is very long the plastic starts to cool very close to the gate and the injection pressure increases. If this time is very short a very high injection pressure is also necessary. In this work two fil times are used, $0.3 \mathrm{~s}$, which is very close to the optimal fil time range, and $0.5 \mathrm{~s}$, which is more similar to the time used in real injection processes.

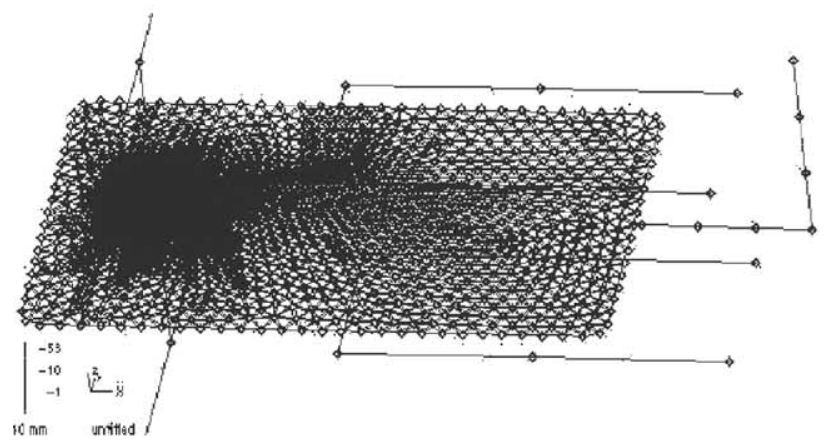

Steel P-20 was selected as the material for the mould and oil as the warming fluid The Arburg $221 \mathrm{E}$ with a maximum injection pressure of $173 \mathrm{MPa}$ and a clamp force of $40,000 \mathrm{t}$ was used for the simulation.

\section{Results and discussion}

The ejection temperature was fi ed at $85^{\circ} \mathrm{C}$ and an average bulk temperature of $5 \mathrm{~s}$ of cooling is suitable for the part to be ejected. The efficien y of the warming and cooling channels 60 and $40 \%$, respectively.

The temperature difference between the hottest and the coolest elements at the end of the fillin process is one of the parameters most sensitive to the change in thickness. Fig. 3 shows the temperature difference for fillin times of $0.5 \mathrm{~s}$ (Fig. 3A) and $0.3 \mathrm{~s}$ (Fig. 3B) using the three different materials.

We can make several conclusions from these figures

- The temperature difference increases rapidly if the thickness of the microchip area is lower than 360-390 $\mu \mathrm{m}$ and it remains almost constant for higher thicknesses. It occurred with all three materials and both fillin times.

- The temperature difference is reduced by half if $0.3 \mathrm{~s}$ is used as the fillin time.

- For G-360 and using a fillin time of $0.3 \mathrm{~s}$ the difference is lower than $25^{\circ} \mathrm{C}$ if the thickness in the microchip area is higher than $390 \mu \mathrm{m}$. This means that the piece will be free of thermal residual stresses.

Another sensitive parameter is the injection pressure. The pressure differences between the elements with the maximum and the minimum pressure at the end of the fillin time are shown in Fig. 4 for the three materials at fillin times of $0.3 \mathrm{~s}$ (Fig. 4A) and $0.5 \mathrm{~s}$ (Fig. 4B). The change in behaviour point in the plot is not as well define as the temperature plot, mainly because the scale ranges of the pressure change are different for each material. In any case, the thickness with which the pressure starts to ground when the thickness decreases is around 360-390 $\mu \mathrm{m}$, exactly the same range found for the temperature difference. The different scale ranges are due to the different viscosity of the three

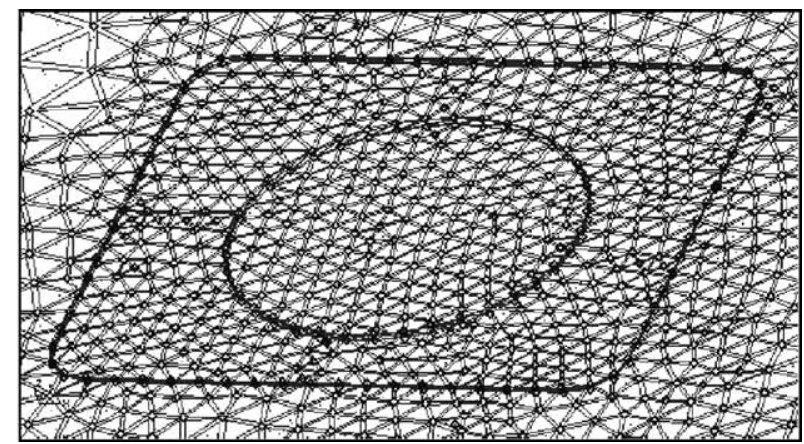

Fig. 2. Mesh for the ISO-MC card and details in the microchip area. 

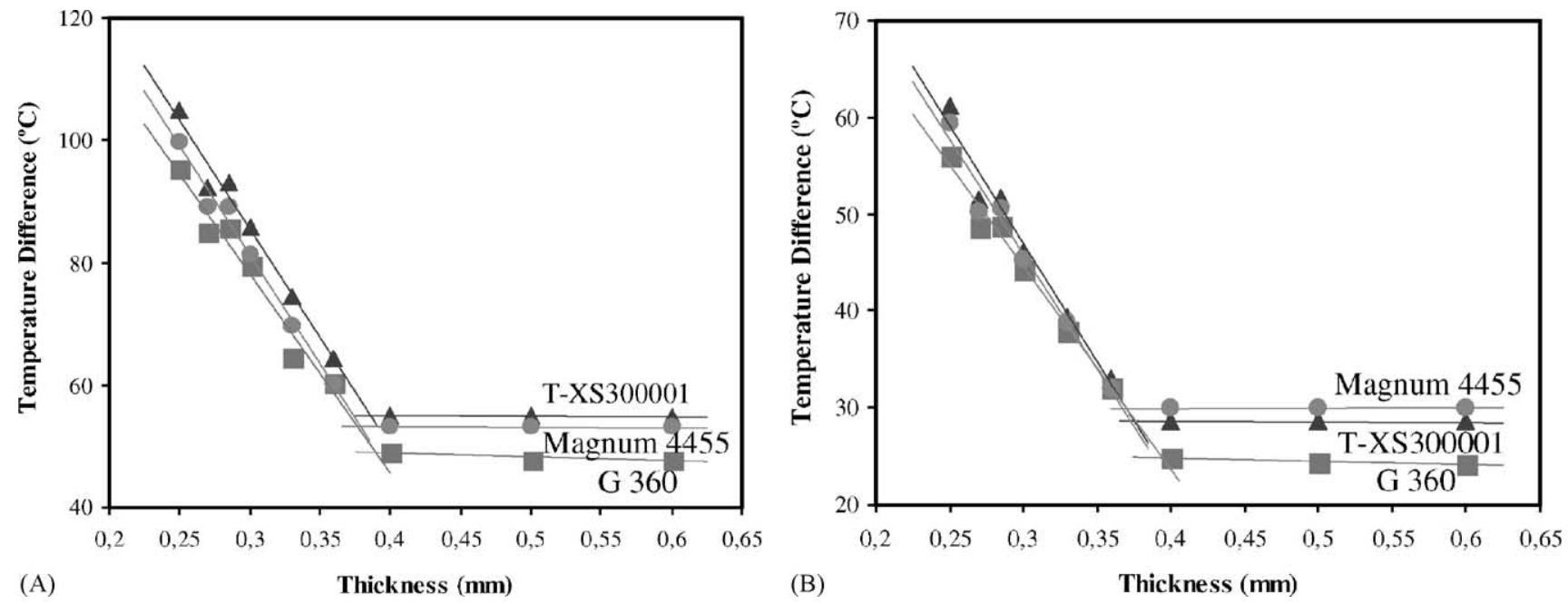

Fig. 3. Influenc of the thickness on the temperature differences for fillin times of $0.5 \mathrm{~s}(\mathrm{~A})$ and $0.3 \mathrm{~s}(\mathrm{~B})$, using the three different materials.
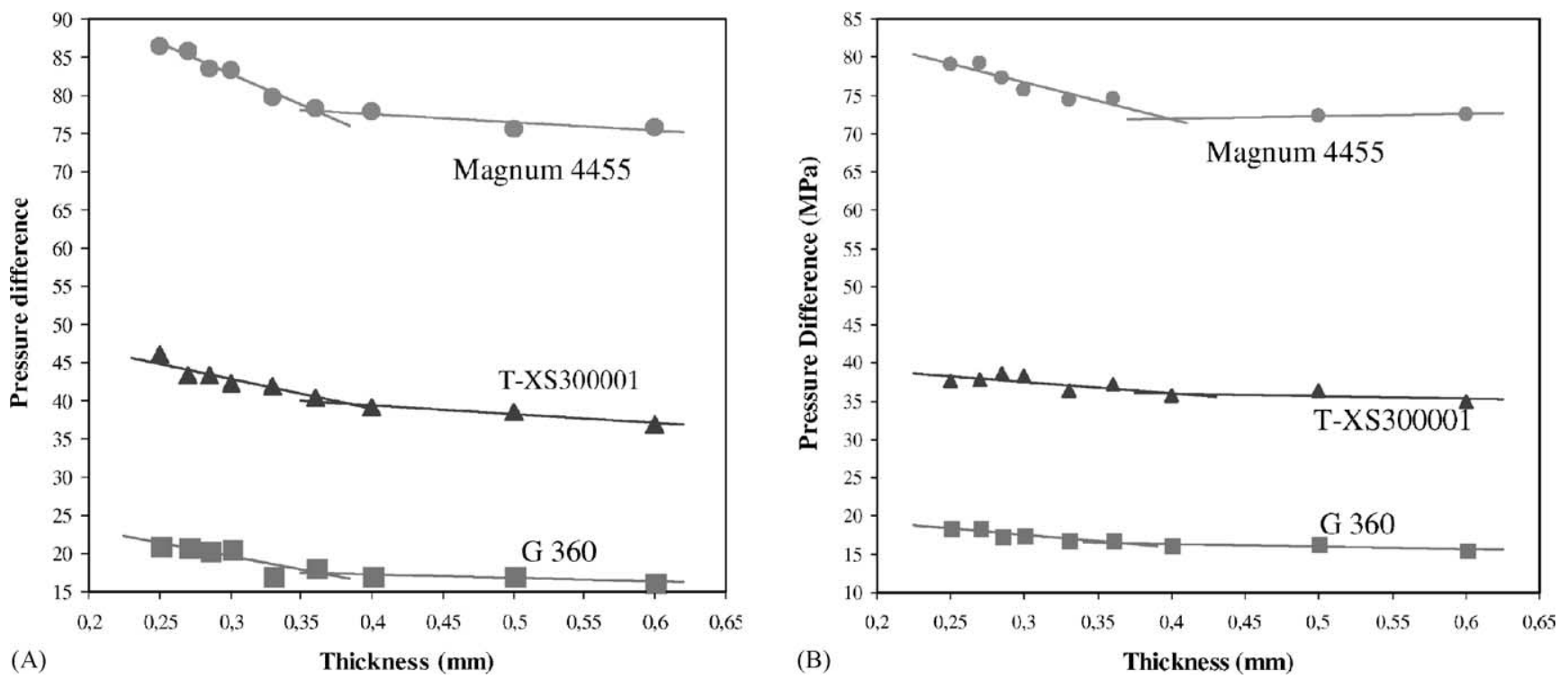

Fig. 4. Influenc of the thickness on the pressure differences for fillin times of $0.5 \mathrm{~s}(\mathrm{~A})$ and $0.3 \mathrm{~s}(\mathrm{~B})$, using the three different materials.

materials. The G-360 is the best because the higher pressure and the pressure differences are the smallest.

Fig. 5 depicts the plot that the pressure distribution calculated for the elements of the mesh at the end of the fillin time. In other conditions the plot is similar but the pressure

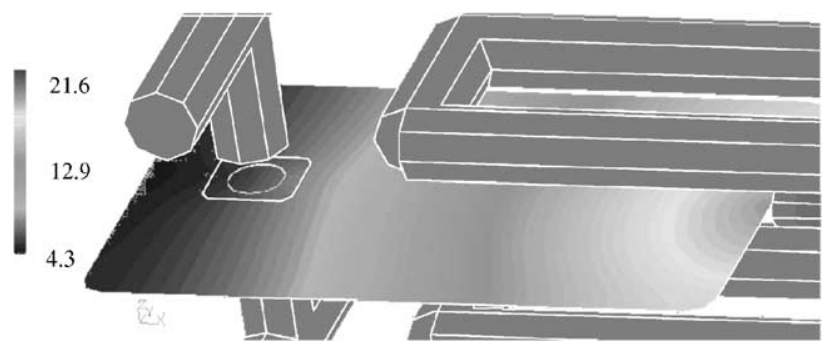

Fig. 5. Pressure distribution at the end of the fillin time $(0.5 \mathrm{~s})$ of the $0.33 \mathrm{~mm}$ thickness using Cyclolac G360 GE. gradient is higher and the isobar lines are not so flat especially in the microchip area.

We also studied the evolution of the air traps, the weld lines and the melt lines but their quantificatio is very diffi cult. The main conclusion, for any material and fillin time, is that

- the air traps disappear from the microchip area with thicknesses of $400 \mu \mathrm{m}$ and higher,

- the weld and melt lines are seriously reduced with microchip thicknesses higher than $400 \mu \mathrm{m}$.

\section{Conclusions}

The CAE tools do not only help design the moulds and optimise the process conditions, they also allow us to 
estimate the same limits in injection moulding processes as the minimum thickness.

It is possible to estimate the same critical values in the injection process by plotting the value of some variables obtained by simulation versus a geometrical condition as the minimum thickness. The variation in the pressure and temperature during the fillin process was seen as the most sensitive parameter for our system (geometry-material-process conditions).

The plot of pressure and temperature differences versus the minimum thickness allows us to estimate the critical thickness as $360-390 \mu \mathrm{m}$ for this geometry by using different ABS plastics formulations. The air traps and the weld and melt lines also suggest a critical value for the thickness of the microchip area of around $400 \mu \mathrm{m}$, and it agrees with the knowledge of the processors.

\section{Acknowledgements}

The author wish to thank M.L. Heijnen for the help in the preparation of the manuscript.

\section{References}

[1] L.T. Manzione (Ed.), Applications of Computer Aided Engineering in Injection Molding, Hanser, New York, 1987.

[2] B.H. Lee, B.H. Kim, Polym. Plast. Technol. Eng. 34 (1995) 793-811.

[3] I. Pandelidis, Q. Zou, Polym. Eng. Sci. 30 (1990) 873-882.

[4] I. Pandelidis, Q. Zou, Polym. Eng. Sci. 30 (1990) 883-892.

[5] H. Lee, B.H. Kim, in: Proceedings of the SPE Annual Technical Conference on ANTEC 1995, pp. 554-560.

[6] W.R. Jong, K.K. Wang, SPE Tech. Pap. 36 (1990) 385-389.

[7] L.S. Turng, H.H. Chiang, J.F. Stevenson, SPE Tech. Pap. 1 (1995) 668-672.

[8] L.W. Seow, Y.C. Lam, J. Mater. Process. Technol. 72 (1997) 333341.

[9] M. Gupta, K.K. Wang, SPE Tech. Pap. 2 (1993) 2290-2295.

[10] S.H. Chang, J.R. Hwang, J.L. Doong, J. Grey Syst. 1 (1999) 68-80.

[11] N. García, Estudio del espesor mínimo para una tarjeta de crédito con microchip, mediante simulación por ordenador, Master Tesis untitled, Dir. Dr. Juan Baselga y Dr. Julio Bravo, Univ. Carlos III de Madrid, Julio 1999.

[12] E. González, Selección del material más adecuado y optimización del proceso de inyección de una tarjeta de crédito con microchip, mediante simulación con ordenador, Master Tesis untitled, Dir. Dr. Juan Baselga y Dr. Julio Bravo, Univ. Carlos III de Madrid, Marzo 2000.

[13] M. Pazos, Evaluación de variables críticas en el moldeo por inyección de lentes bicócavas y biconvexas, Master Tesis untitled, Dir. Dr. Juan Baselga y Dr. Julio Bravo, Univ. Carlos III de Madrid, Marzo 2000. 